\title{
Not only Trolls are Trolling the Internet: A study on dark personality traits, online environment, and commentary styles
}

\author{
Anna M. Connysdotter Karlsson ${ }^{2}$ \\ Petri J. Kajonius ${ }^{1,2}$ \\ ${ }^{1}$ Department of Psychology, Lund University, Sweden \\ ${ }^{2}$ Department of Social and Behavioral Studies, University West, Sweden
}

\begin{abstract}
On the Internet, many commentary styles take place on various forums, and abuse is not uncommon. We investigated the personality traits related to individuals' behaviors on Internet forum posting. The Dark Short Tetrad (SD4) were used to predict $(N=212)$ three types of commentary styles: Trolling (malicious posting), Lurking (reading/not posting) and Posting (reading/posting). The results showed that Trolling co-varied with Sadism $(r=.38$ ) and Machiavellianism $(r=.28)$. The results also showed that people high on dark traits are Trolling the Internet. Exploratory mediator analyses further revealed that various aspects of anonymity trivially moderate personality traits and behavior (indirect effects $\beta \approx .10$ ). The overall take-home message is that personality traits, especially dark traits, play a role in how individuals express themselves online. This provides well-needed insight in abusive behaviors in forums on the internet.
\end{abstract}

Keywords: personality, Dark Tetrad, Internet behavior, online environment

Much of today's communication takes place over the Internet. In $2019,98 \%$ of the population in a progressive country like Sweden had access to the Internet via a computer, smartphone or tablet (The Internet Foundation, 2019). About $83 \%$ used Internet for social media and this number is still on the rise. More tools are being created that enable social activity online (Flanagin, 2017). These tools are used to communicate with other individuals (in forums or games) but also to retrieve information. The largest social network in Sweden is still Facebook, though Instagram and Snapshots are increasingly popular (The Internet Foundation, 2019). On the Internet, millions, if not billions, of people create online profiles to express their thoughts and emotions by sharing content in commentary fields on various forums, presumably expressing their personalities (Azucar, Marengo, \& Settanni, 2018). The comment fields in forums like these are designed to let people discuss or express opinions on just about anything, as well as to provide emotional support and entertainment (Phang, Kankanhalli, \& Sabherval, 2009). The drawbacks of this development can be false information, lack of security, risk of crimes and frauds, as well as bullying and victimization (The Internet Foundation, 2019). For researchers, these forums provide opportunities to study behaviors, often in rather anonymous digital environments (Rogers, Smoak, \& Liu, 2006). In order to understand individuals' online behavior to a greater extent, we examine to what degree personality traits can predict forum posting styles. In addition, we examine if forum anonymity increases this relationship.

Correspondence to: Petri Kajonius, Department of Psychology, Lund University, Lund, Sweden, E-mail: petri.kajonius@psy.lu.se, or to Anna Connysdotter Karlsson, E-mail: anna@noxinet.com

\section{Internet behaviors}

Individuals act differently on the Internet than in a face-toface interaction (Markey \& Wells, 2002). There has been some research on associations between behavior on the Internet and personality traits, traits that may form a key to understanding forum posting styles (Buckels, Trapnell, \& Paulhus, 2014; Seigfried-Spellar \& Lankford, 2018). Three commentary styles have been suggested to stand out (Buckels et al., 2014; Lai \& Chen, 2014; Seigfried-Spellar \& Lankford, 2018; Shachaf \& Hara, 2010; Zezulka \& Seigfried-Spellar, 2016). These are "Trolls" (their motive is to seek attention/revenge and are suggested to have personality traits associated with Sadism, low self-esteem, low conscience, and a low moral compass), "Lurkers" (they visit various forums but refrain from writing messages or comments), and "Posters" (they use forums to reveal personal information that often relates to sex life, sexuality, fantasies, family problems, and personal problems, varying in motives). These and other Internet communication styles are shown to be psychologically linked to personality traits (Kosinski, Bachrach, Kohli, Stillwell, \& Graepel, 2013). Studying relevant personality traits is important to gain further understanding of posting-behavior and possibly of abusive behaviors on the Internet.

\section{Dark personality traits}

Paulhus and Williams (2002) published The Dark Triad (DT3) measuring three personality traits as the dark features of an individual's personality. Dark traits can predict what kind of approach and values a person has towards others (Kajonius, Persson, \& Jonason, 2015). The first of the three 
traits is "Machiavellianism" (Mach), characterized by often having a cynical worldview and by striving for power, money and status; they often are cold and pragmatic, and use false play and manipulation. They can be charming, cunning, strategic, enthusiastic and deficient in morals. The second of these traits is "Narcissism" (Narc), characterized by seeking attention and admiration, by being arrogant and exhibitionistic, and by striving for power and leadership. They often feel superior, dominant and self-righteous. They can be charismatic, productive and inspiring. Thirdly, "Psychopathy" (Psych), characterized by often being cold, and by being manipulative, and impulsive. They often have a low degree of empathy and little feelings of guilt. According to Paulhus and Williams (2002), these traits should be studied as a composite measure, as it may otherwise be difficult to distinguish and clarify their unique contributions, which has been criticized (Persson, 2019; Persson, Kajonius, \& Garcia, 2019). Persson (2019) and Persson et al. (2019) show that the construct aspect should be seen as two different constructs, and not be summed up (Paulhus \& Williams, 2002).

Studies have also suggested that Sadism should be included in the set of dark traits (Buckels, Jones, \& Paulhus, 2013; Chabrol, Van Leeuwen, Rodgers, \& Séjourné, 2009; van Geel, Goemans, Toprak, \& Vedder, 2016; Paulhus, Buckels, Trapnell, \& Jones, in press). Apart from the first three traits, Sadism can predict insensitivity to the suffering of others, and can also predict insensitivity when to "strike back" when threatened (Buckels et al., 2013). Sadism also has shown a unique relation to Internet Trolling (Buckels et al., 2013) and to sexuality (Paulhus et al., 2020). The unique aspect of Sadism is that the individual enjoys the suffering of others. It is therefore seen as justified to include this trait in studies regarding behavior in an Internet environment.

\section{Internet environment}

The anonymity aspect of the online environment is reported to affect the behavior on internet (Seigfried-Spellar \& Lankford, 2018). This could be due to de-individuation processes (Demetriou \& Silke, 2003), inducing a state where individuals feel anonymous among many people. Postmes and Spear (1998) claim that de-individuation must not necessarily lead to unethical behavior on the Internet. However, de-individuation may lead to online disinhibition effects, meaning that in anonymity, communication is more uninhibited than in a face-to-face communication (Clark-Gordon, Bowman, Goodboy, \& Wright, 2019).

Measures of Online Environment (OE) can be described with three subcategories (Ritter, 2014). One is "Acceptability" (relates to the hegemonic culture of the forum. Individuals who score high on OE-acceptability may feel it is okay to express themselves with both prejudice and sexist comments). A second is "Aloneness" (encourages harassment, as the OE is lacking social codes, creating inhibitory effects. Individuals do not feel they need to follow ordinary social norms and can write whatever they want). The third is "Anonymity" (neutralizes status disparities and makes individuals feel invisible while also reducing personal responsibility. Individuals participate in more risky behavior and treat people any way they want since no one knows who they are).

\section{The present study}

The purpose of this study is to predict forum posting behaviors by personality traits, and in addition to explore whether such relationships are mediated by anonymity in the online environment. We are working from the hypothesis that the individual feels secure in the anonymity and therefore write more comments that may seem malicious from other readers' points of view. To answer this, we pose two research questions: a) Can individuals' personality traits predict Internet posting behavior? b) Does online environment have a mediating effect for personality traits and Internet postingbehavior?

\section{METHOD}

\section{Procedure}

The study was performed by an internet survey, advertised on platforms such as Facebook and Discord. In addition, all individuals who received information on the study could send it to whoever they wanted. By completing the survey, which was offered in Swedish and in English, the individuals also had to give their consent to participate. A reminder was sent after two weeks.

\section{Participants}

Out of 220 participants, two individuals did not respond to any questions; one participant only responded to the demographic questions and five participants did not answer any questions regarding Internet behavior. These eight individuals where removed from the study. The study thus included 212 Internet users; they were between 15 to 80 years $(M=$ 38.36 years, $S D= \pm 13.9$ years). The respondents were primarily Swedish speaking (69 \%); 12\% was English speaking; the remainder spoke another language $(18.5 \%)$. Those who filled out the Swedish version of the survey, were on average nine years older (Swedish: $M=41, S D= \pm 13.5$; English: $M=32, S D= \pm 12.5$ ). Of the participants, $73 \%$ were women. $75 \%$ of participants had finished College or University studies. For more details on the sample, see Table A1 in Appendix A.

\section{Measures}

The Dark Tetrad Scale (SD4; O'Meara, Davies, \& Hammond, 2011). This is a 28-item-questionnaire measuring the dark personality traits Machiavellianism, Narcissism, Psychopathy, and Sadism. A 5-point Likert scale was used: "Absolutely Disagree (1)" to "Absolutely Agree (5)".

The Online Environment Scale (OE; Ritter, 2014). This measure addresses the individual's online environment by 17 items forming the scales for Acceptability, Aloneness, and Anonymity. A 5-point Likert scale was used: "Absolutely Disagree (1)" to "Absolutely Agree (5)". 
Table 1. Descriptives of the Study Variables

\begin{tabular}{rrrrrrr}
\hline & $\mathrm{M}$ & $\mathrm{SD}$ & Skewness & Kurtosis & Min - Max Range & Cronbach's Alpha \\
\hline Machiavellianism (SD4) & 19.11 & 5.03 & .10 & .23 & $7-35$ & .76 \\
Narcissism (SD4) & 17.46 & 5.26 & .21 & -.00 & $7-35$ & .80 \\
Psychopathy (SD4) & 12.14 & 5.05 & 1.22 & 1.19 & $7-30$ & .82 \\
Sadism (SD4) & 13.38 & 5.38 & 1.02 & .95 & $7-35$ & .79 \\
Acceptability (OE) & 15.60 & 4.56 & .33 & -.35 & $7-30$ & .71 \\
Aloneness (OE) & 12.16 & 4.36 & .13 & -.73 & $5-23$ & .72 \\
Anonymity (OE) & 8.20 & 3.18 & .88 & .52 & $4-20$ & .69 \\
Trolls & 18.52 & 6.91 & 2.15 & 7.11 & $13-58$ & .89 \\
LurkerS & 14.47 & 2.86 & -.74 & 1.60 & $4-20$ & .74 \\
PosterS & 10.19 & 2.98 & .37 & .05 & $5-19$ & .67 \\
\hline
\end{tabular}

Note: $N=212 . M=$ mean; $S D=$ standard deviation; SD4 = The Short Dark Tetrad; OE = Online Environment. Cronbach's alpha $(\alpha)$ coefficient was used for the internal reliability of all the measuring instruments.

Internet Behavior (Seigfried-Spellar \& Lankford, 2018). This 23-item-questionnaire measures 3 online Internet posting behavior styles, namely for "Trolls", "Lurkers", and "Posters". Two 5-point Likert scales were used, one running from "Absolutely Disagree (1)" to "Absolutely Agree 5" and the other from "Never (1)" to "Always (5)". See Table 1 for Cronbach's alphas.

\section{Model analysis}

A basic data process was done by a visual survey conducted of the 212 participants' response option in IBM SPSS for missing data. Six responses were missing from the sample and were replaced with means. Both the Swedish and the English survey were used. Three auxiliary analyzes were conducted. The first one was done to investigate differences between the English and Swedish surveys (see Table A2 in Appendix A). The second was done to consolidate current commentary styles in an exploratory factor analysis (see Appendix B). The third was done to perform a confirmatory factor analysis of the OE scale to determine the subcategories (see Appendix C).

Spearman's correlation was implemented according to recommendations by Howitt and Cramer (2010), with respect to the posting style of Trolling (skewness 2.15). To identify outliers, a standard analysis of the suitability of the data was performed. Two outliers ( $>3 \mathrm{SD}$ ) were found in the dependent variable Trolls. Since the outliers were found in the dependent variable, and since Trolling in itself is a deviant behavior, the decision was made to use the entire sample. The ground for this decision comes from a recommendation made in Hoaglin and Iglewicz (1987) regarding normal distribution and the use of samples of less than 300 (Field, 2018).

We followed Gignac and Szodorai's (2016) guidelines to correlational sizes, considering .10 to .19 indicating a weak relationship, .20 to .29 a medium relationship, and .30 and above a strong relationship. The results that were significant at a five percent level were considered a rejection of the null hypothesis (Bryman, 2018).

Three linear regression models were performed, one for each posting-behavior (Trolls, Lurkers, \& Posters), with personality traits (SD4) as independent variables. No multicollinearity was detected (Tolerance: Machiavellianism = .71, Narcissism $=.77$, Psychopathy $=.60$, Sadism $=.53$ ).

In addition, exploratory mediator analyses were performed with personality traits (SD4) as independent variables and each of the internet posting behaviors as dependent variables, mediated by online environment (Anonymity, Aloneness, and Acceptability). These were conducted with the help of structural equation modeling (SEM) in SPSS AMOS v.23 and with PROCESS in SPSS.

Table 2. Spearman's correlation matrix of study variables

\begin{tabular}{|c|c|c|c|c|c|c|c|c|c|c|c|c|}
\hline & 1 & 2 & 3 & 4 & 5 & 6 & 7 & 8 & 9 & 10 & 11 & 12 \\
\hline 1. Gender & - & & & & & & & & & & & \\
\hline 2. Age & $-.20 * *$ & - & & & & & & & & & & \\
\hline 3. Education & -.05 & .04 & - & & & & & & & & & \\
\hline 4. Machiavelli & $.17 *$ & -.11 & .03 & - & & & & & & & & \\
\hline 5. Narcissism & $.22 * *$ & -.13 & .06 & $.36^{* * *}$ & - & & & & & & & \\
\hline 6. Psychopathy & $.37 * * *$ & $-.15 *$ & -.09 & $.24 * * *$ & $.40 * * *$ & - & & & & & & \\
\hline 7. Sadism & $.47 * * *$ & $-.31 * * *$ & -.07 & $.41 * * *$ & $.31 * * *$ & $.56 * * *$ & - & & & & & \\
\hline 8. Acceptability & $.20 * *$ & $-.29 * * *$ & -.13 & $.26 * * *$ & $.25 * * *$ & $.39 * * *$ & $.40 * * *$ & 一 & & & & \\
\hline 9. Anonymity & $.23 * * *$ & $-.14 *$ & -.07 & $.24 * * *$ & $.15^{*}$ & $.30 * * *$ & $.39 * * *$ & $.51 * * *$ & - & & & \\
\hline 10. Aloneness & $.25 * * *$ & $-.30 * * *$ & -.06 & $.27 * * *$ & $.17 *$ & $.32 * * *$ & $.39 * * *$ & $.62 * * *$ & $.51 * * *$ & - & & \\
\hline 11. Trolls & $.27 * * *$ & $-.24 * * *$ & -.04 & $.42 * * *$ & $.17 *$ & $.32 * * *$ & $.54 * * *$ & $.35 * * *$ & $.28 * * *$ & $.36^{* * *}$ & - & \\
\hline 12. Lurkers & .13 & $-.22 * *$ & .12 & $.17 *$ & .08 & -.05 & .11 & $.20 * *$ & .10 & $.21 * *$ & $.33^{* * *}$ & - \\
\hline 13. Posters & $.17^{*}$ & -.04 & -.08 & .13 & .11 & $.30 * * *$ & $.23 * * *$ & $.43 * * *$ & $.20 * *$ & $.30 * * *$ & $.30 * * *$ & $.26^{\circ}-x-1$ \\
\hline
\end{tabular}

Note: Coding: Gender ( 0 = female, 1 = male); Education ( 1 = compulsory school/high school, 2 = college/university/other), Dependent variables are Trolls, Lurkers and Posters. Machiavelli $=$ Machiavellianism.

$* \mathrm{p}<.05, * * \mathrm{p}<.01, * * * \mathrm{p}<.001$ 
Table 3. Regression models predicting three internet forum posting behavior styles

\begin{tabular}{|c|c|c|c|c|c|c|}
\hline & \multicolumn{2}{|c|}{ Trolling } & \multicolumn{2}{|c|}{ Lurking } & \multicolumn{2}{|c|}{ Posting } \\
\hline & Beta $(\beta)$ & $p$ & Beta $(\beta)$ & $p$ & $\operatorname{Beta}(\beta)$ & $p$ \\
\hline Gender & .01 & .89 & .11 & .16 & .02 & .76 \\
\hline Age & -.05 & .44 & -.15 & .04 & .12 & .08 \\
\hline Education & .00 & .96 & .13 & .06 & -.02 & .74 \\
\hline Acceptability (OE) & .05 & .54 & .13 & .16 & .41 & .00 \\
\hline Anonymity (OE) & -.00 & .95 & -.09 & .25 & -.13 & .10 \\
\hline Aloneness (OE) & .02 & .77 & .15 & .10 & .09 & .26 \\
\hline Machiavellianism (SD4) & .28 & .00 & .16 & .04 & .03 & .68 \\
\hline Narcissism (SD4) & -.06 & .29 & .00 & .96 & -.08 & .24 \\
\hline Psychopathy (SD4) & .09 & .19 & -.17 & .05 & .22 & .01 \\
\hline Sadism (SD4) & .41 & .00 & .01 & .94 & .00 & .96 \\
\hline Intercept & 1.28 & .20 & 8.78 & .00 & 3.22 & .00 \\
\hline$R^{2}$ & \multicolumn{2}{|c|}{$.45(.42)$} & \multicolumn{2}{|c|}{$.16(.12)$} & \multicolumn{2}{|c|}{$.25(.22)$} \\
\hline $\mathrm{F}$ & \multicolumn{2}{|c|}{14.08} & \multicolumn{2}{|c|}{2.81} & \multicolumn{2}{|c|}{3.15} \\
\hline
\end{tabular}

Note. $\beta=$ standardized beta coefficients, $p=$ significance value. Numbers in parentheses are adjusted $R^{2}$. Figures marked in bold are the significant correlations.

\section{RESULTS}

The matrix with correlations between the study variables is provided in Table 2 . The results showed that particularly Trolling had significant correlations with all four personality traits in SD4. Lurkers showed significant correlations with Machiavellianism and Posters with Psychopathy and Sadism.

In the three regression analyses, one for each online forum behavior style (see Table 3), particularly two dark personality traits markedly related to posting behaviors. Sadism co-varied strongly with Trolling, and Machiavellianism co-varied on a medium level. Psychopathy co-varied on a medium level with Posters. All four dark personality traits, all three Online Environment variables, and the demography indicators (gender, age, and education), could explain the variance in Trolling at 45\%, Lurking 16\%, and Posting 25\%, respectively.

\section{Exploratory mediator analyses with online environment}

Exploratory mediator analyses where conducted to further understand the association between personality traits and posting behaviors. The three online environment mediators (Acceptability, Anonymity, \& Aloneness) were tested in turn. The indirect effect should exceed $\beta=.10$, otherwise it was considered trivial (Gignac \& Szodorai, 2016). Most models showed no indirect effect exceeding $\beta=.10$. The one exception was found between the Psychopathy-trait and Posting via Acceptability $(\beta=.13)$. Figure 1 shows the mediator analysis and the standardized path coefficients.

\section{DISCUSSION}

The goal of this study was to investigate if individuals' personality traits (The Dark Tetrad; SD4) could predict Internet

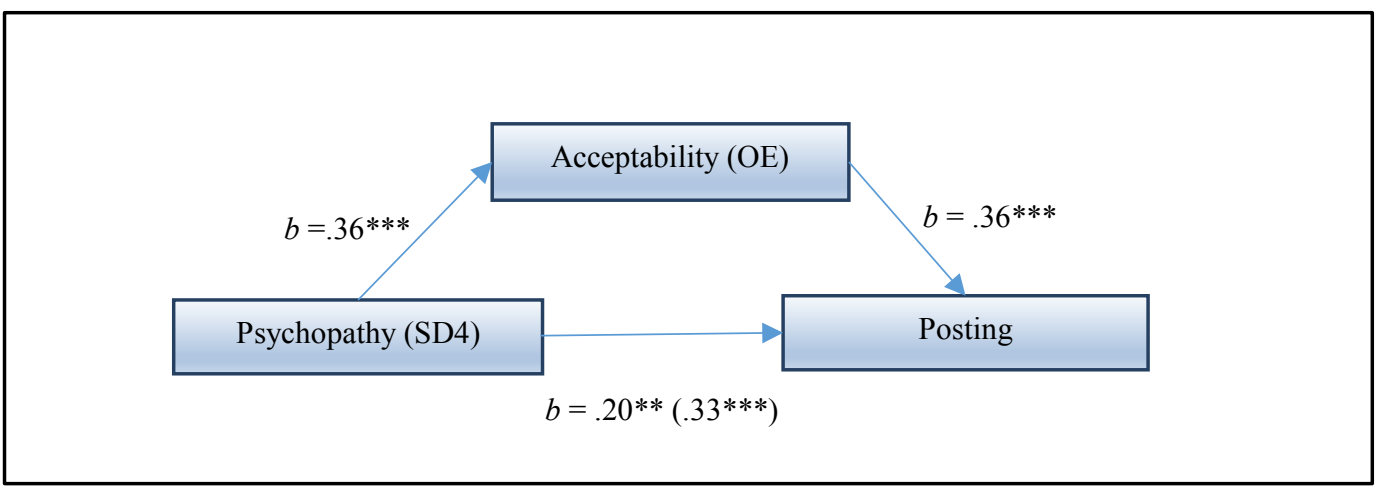

Figure 1. Mediator Analysis between Psychopathy and forum Posting with Online Environment (OE). *** $p=<.01, * * *$ $p=<.001 . b=$ standardized beta. The model shows standardized beta coefficients. The value in parenthesis shows the beta coefficient before the mediator was included in the model. 
forum posting behaviors, and whether this prediction is influenced by being anonymous (as measured by the pertaining OE scale). The results showed that particularly Trolling (malicious posting) had significant correlations with almost all four dark personality traits. Controlling for dark personality traits, Sadism and Machiavellianism remained as the strongest predictors for Trolling. This is in line with Buckels et al.'s (2014) results that also showed a strong correlation with the Internet behavior style, and it provides more evidence of the importance of the role of especially dark personality traits. Not surprisingly, it seems that hard-minded people post more malicious content. Similarly, two of the dark personality traits, Sadism and Psychopathy, co-varied strongly with Posting (regular reading and posting on forums). Interestingly, it seems that hard-minded people also post more in conventional styles. This goes somewhat against Buckels et al.'s (2014) results that did not show any relation between Sadism and Posting.

When the Online Environment was investigated as a mediator in these relationships, only trivial effects were found. This means that personality behind posting behaviors generally cannot be explained by how people see or feel or perceive their online environment on Internet forums. The one exception was Acceptability, which describes tolerance to harmful and socially unacceptable behavior on the Internet (Ritter, 2014), which had a small mediating effect explaining Psychopathy and conventional Posting.

This study makes several contributions to research on individual behavior on the Internet. First, this study shows that an individual's behavior on the Internet can be predicted by dark personality traits. The fact that Trolling is related to the dark traits is already known, but what is of interest is that these dark traits (especially Sadism and Psychopathy) are also represented in the regular Posters. Second, the present study also shows in an exploratory way that Online Environment cannot explain the relationship between the dark traits and the posting behavior. It seems that personality traits are "all it takes" for Internet commentary styles.

Some of the concerns of the present study regarding generalizability are the large age range of the respondents (from 15 to 80 years), their geographical distribution (they come from all over the world), and the differences in level of education. Similarly, effects of self-selection bias in the study warrant further caution with respect to what can be concluded (See Simons, Shoda, \& Lindsay, 2017). This generalizability issue needs to be further investigated. Also, selfdescriptive questionnaires are known for method-variance and for being subject to self-delusion. With respect to the latter, for instance, if a Poster writes a comment that others could see as harassment, while the Poster believes it is an honest and humble opinion, who is correct? Are these posts really a manifestation of psychopathy then?

A limitation may be that in this study only self-evaluations of the individuals' Internet behavior style were used to determine posting styles. In future studies the reader's personality could also be assessed, as Trolling may lie to a great degree in the eye of the beholder (cf. Rauthmann, 2012).

A practical aspect of the present study is that forum posting, and research on forum posting, could be done through chatting in real time. Some studies suggest that persons high on dark traits do not lack the ability to behave themselves, they are just not inclined to do so (Kajonius \& Björkman,
2020). Chats are more expedient and could lower the inclination for certain personality types to be malicious. It could of course also enhance certain personality types. Another suggestion for future research in relation to trolling is personality studies with pure "Gamers" (main reason to be online is to play games) versus pure "Netters" (Internet users whose main reason to be online is something other than gaming). It seems, nevertheless, reasonable to assume that people high on dark traits are Trolling the Internet, no matter what the commentary style is called.

\section{ACCOUNTS AND ACKNOWLEDGMENT}

The work on this article was supported by Grant 2014/14/M/HS6/00919 from the National Science Centre, Poland.

Thanks to the department of psychology at the University West, Trollhättan, Sweden for making this study possible. Thanks to Professor Anna Dåderman for kindly helping in early phases of the project.

\section{Authors contribution}

Both authors contributed to the study conception and design. Material preparation and data collection and the analysis were performed by Petri Kajonius and Anna Karlsson. The first draft of the manuscript was written by Anna Karlsson in Swedish and Petri Kajonius wrote the English version. Both authors commented on previous versions of the manuscript, and read and approved the final manuscript.

\section{Ethical considerations}

The guidelines for ethical considerations were implemented, based on the Swedish Research Council's research practice (The Swedish Research Council, 2017).

\section{Conflict of interest}

Both authors declare to have no conflicts of interest

\section{Data}

The dataset generated and/or analyzed during the current study will be available from the corresponding author on reasonable request.

\section{REFERENCES}

Azucar, D., Marengo, D., \& Settanni, M. (2018). Predicting the Big 5 personality traits from digital footprints on social media: A meta-analysis. Personality and Individual Differences, 124, 150-159.

Buckels, E., Jones, D., \& Paulhus, D. (2013). Behavioral Confirmation of Everyday Sadism. Psychological Science, 24, 22012209. https://doi-/10.1177\%2F0956797613490749

Buckels, E. E., Trapnell, P. D., \& Paulhus, D. L. (2014). Trolls just want to have fun. Personality and Individual Di $\square$ erences, 67, 97-102. http://dx.doi.org/10.1016/j.paid.2014.01.016

Bryman, A. (2018). Samhällsvetenskapliga metoder [Social Research Methods] (3 ${ }^{\text {rd }}$ Ed.)). Malmö: Liber AB. 
Chabrol, H., Van Leeuwen, N., Rodgers, R., \& Séjourné, N. (2009). Contributions of psychopathic, narcissistic, Machiavellian, and sadistic personality traits to juvenile delinquency. Personality and Individual Differences, 47, 734-739. https://doi/10.1016/j.paid.2009.06.020

Clark-Gordon, C., Bowman, N., Goodboy, A., \& Wright, A. (2019). Anonymity and Online Self-Disclosure: A Meta-Analysis. Communication Reports, 32, 98-111

Cohen, R. J., \& Swerdlik, M. E. (1995). Psychological testing and assessment: an introduction to tests and measurement ( $8^{\text {th }} \mathrm{Ed}$.). New York: McGraw-Hill Higher Education.

Demetriou, C., \& Silke, A. (2003). A criminological Internet "Sting": Experimental evidence of illegal and deviant visits to a website trap. British Journal of Criminology, 43, 213-222.

Flanagin, A. (2017). Online Social Influence and the Convergence of Mass and Interpersonal Communication. Human Communication Research, 43, 450-463.

https://doi-org.ezproxy.ub.gu.se/10.1111/hcre.12116

Field, A. (2018). Discovering statistics using IBM SPSS statistics: and sex and drugs and rock ' $n$ ' roll ( $5^{\text {th }}$ Ed.). London: Sage Publications Ltd. Place

Funder, D. (2012). Accurate Personality Judgment. Current Directions in Psychological Science, 21, 177-182. https://doi-/10.1177\%2F0963721412445309

Gignac, G., \& Szodorai, E. (2016). Effect size guidelines for individual differences researchers. Personality and Individual Differences, 102, 74-78. https://doi- /10.1016/j.paid.2016.06.069

Hoaglin, D., \& Iglewicz, B. (1987). Fine-Tuning Some Resistant Rules for Outlier Labeling. Journal of the American Statistical Association, 82, 1147-1149. 10.2307/2289392

Howitt, D., \& Cramer, D. (2010). Introduction to research methods in psychology $\left(3^{\text {rd }}\right.$ Ed). Harlow: Prentice Hall.

Kajonius, P. J. (2016). Honesty-Humility predicting self-estimated academic performance. International Journal of Personality Psychology, 2, 1-6.

Kajonius, P. \& Johnson, J. (2018). Sex differences in 30 facets of the five factor model of personality in the large public $(N=320,128)$. Personality and Individual Differences, 129, 126130. https://doi.org/10.1016/j.paid.2018.03.026

Kajonius, P. J., \& Björkman, T. (2020). Individuals with dark traits have the ability but not the disposition to empathize. Personality and Individual Differences, 155, 109716.

Kajonius, P. J., \& Johnson, J. A. (2019). Assessing the Structure of the Five Factor Model of Personality (IPIP-NEO-120) in the Public Domain. Europe's Journal of Psychology, 15, 260-275.

Kajonius, P., \& Mac Giolla, E. (2017). Personality traits across countries: Support for similarities rather than differences. PloS one, 12, e0179646.

Kajonius, P. J., Persson, B. N., \& Jonason, P. K. (2015). Hedonism, achievement, and power: Universal values that characterize the dark triad. Personality and Individual Differences, 77, 173-178.

Kosinski, M., Bachrach, Y., Kohli, P., Stillwell, D., \& Graepel, T. (2014). Manifestations of user personality in website choice and behaviour on online social networks. Machine Learning, 95, 357-380.

Lai, H. M., \& Chen, T. T. (2014). Knowledge sharing in interest online communities: A comparison of posters and lurkers. Computers in Human Behavior, 35, 295-306. https://doi-/10.1016/j.chb.2014.02.004

Markey, P., \& Wells, S. (2002). Interpersonal Perception in Internet Chat Rooms. Journal of Research in Personality, 36, 134146. 10.1006/jrpe.2002.2340

Mayer, J. D. (2007). Personality: A systems approach. Boston: Allyn \& Bacon.

McCrae, R., \& Costa, P. (1997). Personality Trait Structure as a Human Universal. American Psychologist, 52, 509-516.

McCrae, R. R., \& John, O. P. (1992). An introduction to the fivefactor model and its applications. Journal of Personality, 60, 175-215. 10.1111/j.1467-6494.1992.tb00970.x
O'Meara, A., Davies, J., \& Hammond, S. (2011). The psychometric properties and utility of the short sadistic impulse scale (SSIS). Psychological Assessment, 23, 523-531. 10.1037/a0022400

Paulhus, D.L., Buckels, E.E., Trapnell, P.D., \& Jones, D.N. (2020). Screening for Dark Personalities: The Short Dark Tetrad (SD4). European Journal of Psychological Assessment. Online first, July 27, 2020

Paulhus, D. L., \& Williams, K., M. (2002). The dark triad of personality: Narcissism, Machiavellianism, and psychopathy. Journal of Research in Personality, 36, 556-563.

https://doi-/10.1016/S0092-6566(02)00505-6

Persson, B. N. (2019). Searching for Machiavelli but finding psychopathy and narcissism. Personality Disorders: Theory, Research, and Treatment, 10, 235-245.

Persson, B. N., Kajonius, P. J., \& Garcia, D. (2019). Revisiting the structure of the Short Dark Triad. Assessment, 26, 3-16.

Phang, C. W., Kankanhalli, A., \& Sabherval, R. (2009). Usability and sociability in online Communities: A comparative study of knowledge seeking and contribution. Journal of the Association for Information Systems, 10, 721-747.

Postmes, T., \& Spears, R. (1998). Deindividuation and antinormative behavior: A meta-analysis. Psychological Bulletin, 123, 238-259.

Rauthmann, J. F. (2012). You say the party is dull, I say it is lively: A componential approach to how situations are perceived to disentangle perceiver, situation, and perceiver $\times$ situation variance. Social Psychological and Personality Science, 3, 519-528.

Ritter, B. (2014). Deviant behavior in computer-mediated communication: development and validation of a measure of cybersexual harassment. Journal of Computer-Mediated Communication, 19, 197-214. https://doi-/10.1111/jcc4.12039

Rogers, M., Smoak, N. D., \& Liu, J. (2006). Self-reported Deviant Computer Behavior: A Big-5, Moral Choice, and Manipulative Exploitive Behavior Analysis. Deviant behavior 27, 245-268. 10.1080/01639620600605333

Seigfried-Spellar, K., \& Lankford, C. (2018). Personality and online environment factors differ for posters, trolls, lurkers, and confessors on Yik Yak. Personality and Individual Differences, 124, 54-56. https://doi-/10.1016/j.paid.2017.11.047

Shachaf, P., \& Hara, N.(2010). Beyond vandalism: Wikipedia trolls. Journal of Information Science, 36, 357-370. https://doi$/ 10.1177 \% 2 F 0165551510365390$

Sibley, C. G., Luyten, N., Purnomo, M., Mobberley, A., Wootton, L. W., Hammond, M. D., Sengupta, N., Perry, R., \& West-Newman, T. (2011). The Mini-IPIP6: Validation and extension of a short measure of the Big-Six factors of personality in New Zealand. New Zealand Journal of Psychology, 40, 142-159.

Simons, D. J., Shoda, Y., \& Lindsay, D. S. (2017). Constraints on generality (COG): A proposed addition to all empirical papers. Perspectives on Psychological Science, 12, 1123-1128.

The Internet Foundation (2019). Svenskarna och internet [The Swedes and the Internet] 2019.

https://svenskarnaochinternet.se/app/uploads/2019/10/svenskarna-och-internet-2019-a4.pdf

The Swedish Researchers Council. (2017). Good Research Practice. Government Offices of Sweden, Ministry of Education and Research. https://www.vr.se/english/analysis/reports/ our-reports/2017-08-31-good-research-practice.html

van Geel, M. V., Goemans, A., Toprak, F., \& Vedder, P. (2016). Which personality traits are related to traditional bullying and cyberbullying? A study with the big five, dark triad and sadism. Personality and Individual Differences, 106, 231-235. 10.1016/j.paid.2016.10.063.

Watson, D., Clark, L. A., Chmielewski, M., \& Kotov, R. (2013). The value of suppressor effects in explicating the construct validity of symptom measures. Psychological Assessment, 25, 929941. https://doi.org/10.1037/a0032781 
Zezulka, L. A., \& Seigfried-Spellar, K. C. (2016). Di $\square$ erentiating cyberbullies and Internet trolls by personality characteristics and self-esteem. Journal of Digital Forensics, Security and Law, 11, $7-26$.

Received December 16, 2020

Accepted December 22, 2020 


\section{APPENDIX A: Swedish and English surveys}

Table A1. Differences in Swedish and English questionnaires respectively

\begin{tabular}{lrrrc}
\hline & \multicolumn{2}{c}{ Swedish survey } & \multicolumn{2}{c}{ English survey } \\
\cline { 2 - 5 } Background variables & $n$ & $\%$ & 32 & $\%$ \\
\hline Gender & 24 & 16 & 27 & 43 \\
Man & 128 & 84 & 1 & 0.5 \\
Woman & - & - & & \\
Transgender & & & 9 & 15 \\
Mother tongue & 137 & 90 & 26 & 43 \\
$\quad$ Swedish & - & - & 25 & 42 \\
English & 14 & 9 & 18 & 30 \\
All other languages & & & 25 & 41.5 \\
Employment & 43 & 28 & 7 & 11.5 \\
Student & 79 & 52 & 1 & 2 \\
Working & 8 & 5 & 9 & 15 \\
Unemployed & 8 & 5 & 19 & 32 \\
Senior & 14 & 9 & 12 & 20 \\
Other & & & 21 & 35 \\
Form of living & 6 & 4 & 3 & 5 \\
With parent / parents & 30 & 20 & 1 & 1.5 \\
Single & 103 & 68 & 4 & 6.5 \\
Married / with partner & 2 & 1 & 4 & \\
Student home / collectiv & 6 & 3 &
\end{tabular}

Among the background questions, some differences were found between the two questionnaires. More of those who answered the English survey lived at home with a parent or caregiver (Swedish survey $4 \%$, English survey $32 \%$ ). In the Swedish survey, more individuals lived with someone else as married or cohabiting (the Swedish survey $68 \%$, the English survey $35 \%$ ). There was also a big difference among the sexes of which in the Swedish survey only $16 \%$ were men while in the English survey $53 \%$ were men. Nine Swedes piloted the English survey and these answers were included in the English study. To find out whether there were any differences between the two studies regarding internet roles, independent $t$-tests and significance tests were made.

The differences found among the $t$-tests have a probable explanation in the sample characteristics. In the English survey, most participants were men (53\%), in contrast to the Swedish survey (16\%); also, the mean age was lower in the English $(M=32, S D= \pm 12.5)$, compared to the Swedish $(M=41, S D= \pm 13.5)$.

Table A2. T-test between the Swedish and the English survey

\begin{tabular}{|c|c|c|c|c|c|c|}
\hline & \multicolumn{2}{|c|}{ Swedish $(N=152)$} & \multicolumn{2}{|c|}{ English $(N=60)$} & \multicolumn{2}{|c|}{ t-test } \\
\hline SCALES & $M$ & $S D$ & $M$ & $S D$ & $t$ & $p$ \\
\hline \multicolumn{7}{|c|}{ DT4 - "The Dark Tetrad" } \\
\hline Machiavellianism & 18.3 & 4.7 & 21.3 & 5.2 & $\mathrm{t}(210)=-4.01$ & .689 \\
\hline Narcissism & 17.2 & 4.9 & 18.1 & 6.0 & $\mathrm{t}(210)=-1.19$ & .143 \\
\hline Psychopathy & 11.0 & 4.0 & 15.0 & 6.2 & $t(78.65)=-4.62$ & .000 \\
\hline Sadism & 12.0 & 4.4 & 16.9 & 6.0 & $t(84.98)=-5.68$ & .001 \\
\hline \multicolumn{7}{|c|}{ OE-scale - "Online Environment Scale" } \\
\hline Acceptability & 14.3 & 3.8 & 18.9 & 4.8 & $t(89.3)=-6.72$ & .016 \\
\hline Anonymity & 7.6 & 2.9 & 9.7 & 3.3 & $t(210)=-4.53$ & .095 \\
\hline Aloneness & 11.4 & 4.1 & 14.0 & 4.5 & $\mathrm{t}(210)=-3.99$ & .638 \\
\hline \multicolumn{7}{|c|}{ Internet Posting Behavior Style } \\
\hline Trolls & 17.2 & 5.1 & 21.9 & 9.3 & $\mathrm{t}(73.5)=-3.70$ & .000 \\
\hline Lurkers & 14.4 & 3.0 & 14.8 & 2.5 & $\mathrm{t}(210)=-0.89$ & .183 \\
\hline Posters & 9.7 & 2.8 & 11.5 & 3.1 & $\mathrm{t}(210)=-4.12$ & .212 \\
\hline
\end{tabular}




\section{APPENDIX B: Factor analysis of the Internet roles}

When a scale coding for the Yik Yak A, B and C scales (Seigfreid-Spellar \& Lankford, 2018) was missing, an exploratory strategy was adopted through a factor analysis according to Dåderman's (2019) recommendations. An explorative principal axis component analysis with varimax rotation was performed in SPSS on 22 (initially 23) questions and statements. The sample consisted of 212 individuals between the ages of 15 and 80 years $(M=$ 38.36 years, $S D= \pm 13.9$ years); $73 \%$ were women. Principal axis factor analysis was used for the purpose of estimating the number of factors. Before the factor analyses, standard analyses for the suitability of the test of the data material were performed. In their study, Seigfried-Spellar and Lankford (2018) had four Internet roles (Trolls, Lurkers, Confessors, and Posters). Despite several attempts, the results did not follow Seigfried-Speller and Lankford's theory of four roles. Instead, the present study yielded results on three factors that retained the majority of the items. One statement ("If I am upset with a friend / partner / colleague / teacher, I write something negative about them.") was removed from the factor analysis as it had three low loadings (see Table B1).

The three factors accounted for $50 \%$ of the items of a principal component analysis with varimax rotation. Because the sample was suitable for factor analyses, Kaiser-Meyer-Olkin (KMO), measuring sample adequacy, showed .81, which indicates suitability for factor analysis (Hutcheson \& Sofroniou, 1999). Bartlett's test of sphericity showed a significance of $\mathrm{p}<.001$. According to Field (2018), RMSEA should be as close as possible to 0 and CFI as close as possible to 1 . The best result the present study obtained in this measurement was with this three-factor analysis: RMSEA .127 and CFI .670.

The three factors were then tested in AMOS (see Figure B1). The figure shows the level of charges between the various questions and statements that were included, as well as the three factors. The highest loading was .88 and the lowest was .35. At a minimum, a loading should be .30 (Field, 2018).

Table B1. The loadings in a factor analysis of the YikYak scales (Seigfried-Spellar \& Lankfort, 2018)

\begin{tabular}{|c|c|c|c|c|}
\hline \multicolumn{2}{|c|}{ Question / Statement } & Trolls & Lurkers & Posters \\
\hline YYB.2 & I enjoy reading offensive comments for the fun of it. & .82 & & \\
\hline YYC.3 & How much do you enjoy reading offensive comments? & .81 & & \\
\hline YYC.10 & How much do you enjoy reading racist or sexist comments? & 79 & & \\
\hline YYB.4 & I enjoy reading sexual comments for the fun of it & .67 & & \\
\hline YYB.1 & I enjoy posting offensive comments for the fun of it. & .65 & & \\
\hline YYB.6 & I enjoy reading negative comments about people. & .65 & & \\
\hline YYC.7 & How much do you enjoy reading comments that upset people? & .62 & & \\
\hline YYB.3 & I enjoy posting sexual comments for the shock value. & .61 & & \\
\hline YYC.8 & $\begin{array}{l}\text { How often have you posted a comment that might be considered racist or sexist, } \\
\text { according to yourself? }\end{array}$ & .58 & & \\
\hline YYC.6 & How much do you enjoy posting comments just to upset people? & .57 & & \\
\hline YYB.7 & There are comments that are offensive but they are really harmless. & .53 & & \\
\hline YYC.2 & How much do you enjoy posting offensive comments? & .53 & & \\
\hline YYC.9 & $\begin{array}{l}\text { How often have you posted a comment that might be considered racist or sexist } \\
\text { according to others? }\end{array}$ & .51 & & \\
\hline YYA.5 & I enjoy reading other people's comments. & & .73 & \\
\hline YYC.5 & How much do you enjoy reading others debate issues? & & .73 & \\
\hline YYC.1 & How much do you enjoy reading other people's comments? & & .73 & \\
\hline YYA.1 & I spend more time reading other people's comments than posting my own. & & .69 & \\
\hline YYA.2 & I post comments all the time. & & & .75 \\
\hline YYA.4 & I enjoy replying to other people's comments. & & & .70 \\
\hline YYC.4 & How much do you enjoy debating issues? & & & .61 \\
\hline YYA.3 & I have never posted a comment. & & & -.54 \\
\hline YYC.11 & $\begin{array}{l}\text { How frequently do you use social media as a way to confess things that you would- } \\
\text { n't publicly talk about? }\end{array}$ & & & .45 \\
\hline YYB.5 & $\begin{array}{l}\text { When I am upset at a particular individual such as friend, significant other, col- } \\
\text { league, or professor, I enjoy posting negative comments about them on social me- } \\
\text { dia. }\end{array}$ & .17 & -.01 & .19 \\
\hline
\end{tabular}

Note: Every item from the three Yik Yak Scales are represented here, along with the loadings. 


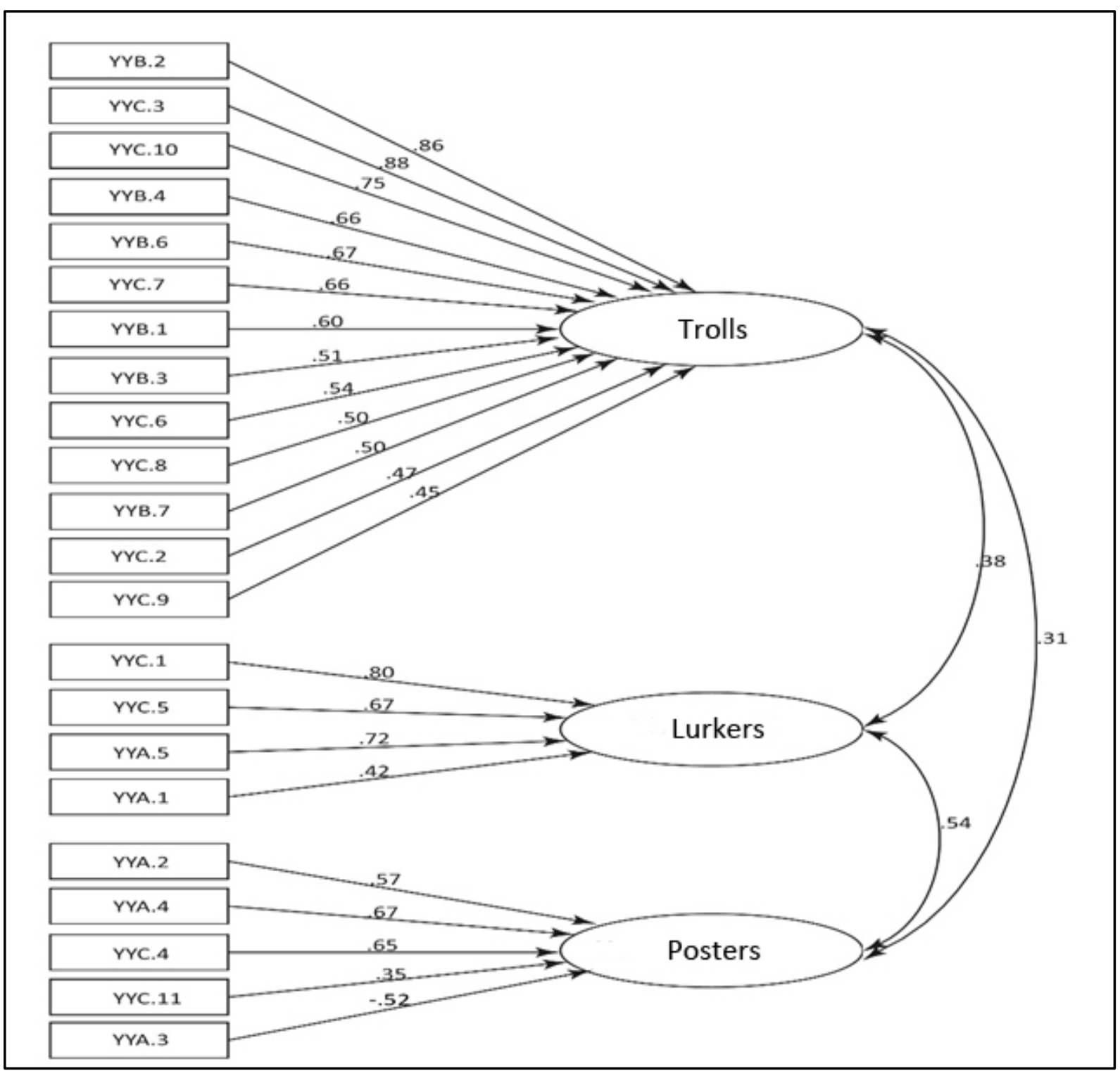

Figure B1. Factor analysis in AMOS. The model shows standardized beta coefficients. Abbreviations: YYA, YYB, and YYC with the numbers refer to the codes of the Yik Yak scales

\section{REFERENCES APPENDIX B}

Dåderman, Anna. (2019). Hur gör jag en faktoranalys i SPSS? [Translation: How do I do a factor analyze in SPSS? School material]. University West. The Institution for Individuals and Society.

Hutcheson, G., \& Sofroniou, N. (1999). The multivariate social scientist. Sage.

Field, A. (2018). Discovering statistics using IBM SPSS statistics: and sex and drugs and rock ' $n$ ' roll (5 $5^{\text {th }}$ Ed.). SAGE Publications Ltd.

Seigfried-Spellar, K., \& Lankford, C. (2018). Personality and online environment factors differ for posters, trolls, lurkers, and confessors on Yik Yak. Personality and Individual Differences, 124, 54-56.

https://doi-org.ezproxy.ub.gu.se/10.1016/j.paid.2017.11.047 


\section{APPENDIX C: Confirmatory factor analysis of the OE scale}

There were some differences between Ritter's (2014) subcategories and Seigfried-Spellar and Lankford's (2018) subcategories in the Online Environment scale (Ritter, 2014). Ritter created the OE item, to which Seigfried-Spellar and Lankford added three items. Another difference was that Ritter had four subcategories, while Seigfried-Spellar and Lankford only collected data on three.

At the time of the survey's advertisement the subcategories had been based on Seigfried-Spellar and Lankford's (2018) results on three subcategories, as well as on the number of questions each subcategory then had. There were questions that were difficult to translate into Swedish, and there were superfluous questions within a specific subcategory. Because of this, three questions were removed. Table $\mathrm{C} 1$ lists all items that have been included in the three different studies, together with the subcategories they belong to after a confirmatory factor analysis.

Table C1. All statements included in the three different studies

\begin{tabular}{|c|c|c|}
\hline Ritter (2014) & Seigfried-Spellar \& Lankford, 2018 & Current study \\
\hline \multicolumn{3}{|c|}{ Acceptability } \\
\hline $\begin{array}{l}\text { It is safe to express prejudice against } \\
\text { others online. }\end{array}$ & $\begin{array}{l}\text { It is safe to express prejudice against oth- } \\
\text { ers online. }\end{array}$ & It is safe to express prejudice against others online. \\
\hline $\begin{array}{l}\text { It is acceptable to use stereotypes on } \\
\text { the Internet. }\end{array}$ & $\begin{array}{l}\text { It is acceptable to use stereotypes on the } \\
\text { Internet. }\end{array}$ & It is acceptable to use stereotypes on the Internet. \\
\hline \multirow[t]{2}{*}{$\begin{array}{l}\text { It is safe to express prejudice against } \\
\text { women online. }\end{array}$} & $\begin{array}{l}\text { It is safe to express prejudice against } \\
\text { women online. }\end{array}$ & $\begin{array}{l}\text { It is safe to express prejudice against women } \\
\text { online. }\end{array}$ \\
\hline & $\begin{array}{l}\text { I feel good when I can express what I re- } \\
\text { ally feel on the internet. }\end{array}$ & $\begin{array}{l}\text { I feel good when I can express what I really feel on } \\
\text { the internet. }\end{array}$ \\
\hline \multirow[t]{3}{*}{$\begin{array}{l}\text { Blatant sexism, not acceptable in tra- } \\
\text { ditional settings, is allowed online. }\end{array}$} & $\begin{array}{l}\text { Blatant sexism, not acceptable in tradi- } \\
\text { tional settings, is allowed online. }\end{array}$ & $\begin{array}{l}\text { Blatant sexism, not acceptable in traditional set- } \\
\text { tings, is allowed online. }\end{array}$ \\
\hline & $\begin{array}{l}\text { It feels safe to talk about things on the in- } \\
\text { ternet that I wouldn't talk about in real } \\
\text { life. }\end{array}$ & $\begin{array}{l}\text { It feels safe to talk about things on the internet that } \\
\text { I wouldn't talk about in real life. }\end{array}$ \\
\hline & & $\begin{array}{l}\text { I can allow my true personality characteristics to } \\
\text { emerge online. }\end{array}$ \\
\hline
\end{tabular}

\begin{tabular}{ll}
\hline & \multicolumn{1}{c}{ Anonymity } \\
\hline $\begin{array}{l}\text { There is little personal accountability } \\
\text { for one's actions online. }\end{array}$ & $\begin{array}{l}\text { There is little personal accountability for } \\
\text { one's actions online. }\end{array}$ \\
$\begin{array}{ll}\text { There are little or no consequences } \\
\text { for online behavior. }\end{array}$ & $\begin{array}{l}\text { There are little or no consequences for } \\
\text { online behavior. }\end{array}$
\end{tabular}

I can engage in behavior seen as risky in the outside world when I am online.

There are no repercussions for my behavior online.
There are no repercussions for my behavior online.

I can treat people however I want on the Internet because they don't know who I really am.

I can allow my true personality characteristics to emerge online.

It is acceptable to demonstrate anti-minority behavior online. *

It is acceptable to use stereotypes on the Internet. *
There is little personal accountability for one's actions online.

There are little or no consequences for online behavior.

I can engage in behavior seen as risky in the outside world when I am online.

There are no repercussions for my behavior online.

I can treat people however I want on the Internet because they don't know who I really am. 
Table C1 continued

$\begin{aligned} & \text { I have to choose my words more } \\ & \text { carefully in a face-to-face situation } \\ & \text { than I do online. }\end{aligned}$
$\begin{aligned} & \text { There is a higher standard for face- } \\ & \text { online. }\end{aligned}$
$\begin{aligned} & \text { There is a higher standard for face-to- } \\ & \text { to-face behavior relative to online be- } \\ & \text { havior. }\end{aligned}$
face behavior relative to online behav-
I can say what I want on the internet be- I can say what I want on the internet because it is
cause it is easy to get out of the situation. easy to get out of the situation.
There is something exhilarating about There is something exhilarating about sharing
sharing views online that I could not views online that I could not openly express face-
openly express face-to-face.
I tore-face.
situation more than when I'm on the in- more than when I'm on the internet.
ternet.
It is easy to act however you want on the It is easy to act however you want on the internet
internet because others are not physically because others are not physically present.
present.

\begin{tabular}{|c|c|c|}
\hline \multicolumn{3}{|c|}{ Affective Stimulation } \\
\hline $\begin{array}{l}\text { I have support from others online no } \\
\text { matter what I say.** }\end{array}$ & Moved to Acceptability & $\begin{array}{l}\text { After confirmatory factor analysis confirmed as } \\
\text { Acceptability }\end{array}$ \\
\hline $\begin{array}{l}\text { I can allow my true personality char- } \\
\text { acteristics to emerge online.** }\end{array}$ & Moved to Anonymity & $\begin{array}{l}\text { After confirmatory factor analysis moved to Ac- } \\
\text { ceptability }\end{array}$ \\
\hline $\begin{array}{l}\text { I can engage in behavior seen as risky } \\
\text { in the outside world when I am } \\
\text { online.** }\end{array}$ & Moved to Anonymity & $\begin{array}{l}\text { After confirmatory factor analysis confirmed as } \\
\text { Anonymity }\end{array}$ \\
\hline $\begin{array}{l}\text { There is something exhilarating } \\
\text { about sharing views online that I } \\
\text { could not openly express face-to- } \\
\text { face. }{ }^{*}\end{array}$ & Moved to Aloneness & $\begin{array}{l}\text { After confirmatory factor analysis confirmed as } \\
\text { Aloneness }\end{array}$ \\
\hline $\begin{array}{l}\text { I feel good when I express how I re- } \\
\text { ally feel online.** }\end{array}$ & Moved to Acceptability & $\begin{array}{l}\text { After confirmatory factor analysis confirmed as } \\
\text { Acceptability }\end{array}$ \\
\hline $\begin{array}{l}\text { It is easy to act however I want online } \\
\text { because other people are not physi- } \\
\text { cally present.** }\end{array}$ & Moved to Acceptability & $\begin{array}{l}\text { After confirmatory factor analysis confirmed as } \\
\text { Aloneness }\end{array}$ \\
\hline
\end{tabular}

Note. ${ }^{*}=$ statement that was excluded in the Swedish study. $* *=$ Items moved to a subcategory other than the original.

\section{REFERENCES APPENDIX C}

Ritter, B. (2014). Deviant behavior in computer-mediated communication: development and validation of a measure of cybersexual harassment. Journal of Computer-Mediated Communication, 19, 197-214.

https://doi-org.ezproxy.ub.gu.se/10.1111/jcc4.12039

Seigfried-Spellar, K., \& Lankford, C. (2018). Personality and online environment factors differ for posters, trolls, lurkers, and confessors on Yik Yak. Personality and Individual Differences, 124, 54-56. https://doi-org.ezproxy.ub.gu.se/10.1016/j.paid.2017.11.04 